\title{
COVID 19 Detection Application at Siti Fatimah Hospital Method of Using Deep Learning
}

\author{
Jayah Jayah ${ }^{1}$ Leni Novianti ${ }^{1, *}$ \\ ${ }^{1}$ Informatics Management State Polythecnic of Sriwijaya \\ ${ }^{*}$ Corresponding author. Email: leninovianti16@gmail.com
}

\begin{abstract}
12 March 2021 WHO (Whorld Health Organization) declared Covid-19 a pandemic. The SARS-CoV-2 virus has infected 5,817,317 people with 216 countries infected as of May 28, 2020. For this reason, a solution is needed to break this covid chain, one of which is a detection application that can be used as a supporter in decision making to find out people who are infected. indicated this covid-19. This research was conducted at Siti Fatimah Hospital, South Sumatra Province using the method Machine learning by using yahoo Convolutional Neural Network (CNN) which is used as image process.
\end{abstract}

Keywords: covid-19, Machine Learning, Convolutional Neu-ral Networks (CNN).

\section{INTRODUCTION}

Siti Fatimah Hospital is the largest regional government- owned hospital in Indonesia, which stands on an area of 4.1 hectares with a building area of $52,952.11 \mathrm{~m} \mathrm{2}$. Born as proof of the seriousness of the local government to improve the health status of the community, especially in the South Sumatra Province which was inaugurated by the Governor of South Sumatra and witnessed by the Minister of Health of the Republic of Indonesia in 2018. Siti Fatimah Hospital is also one of the referral hospitals in handling covid 19, especially in South Sumatra province as stated in the Decree of the Governor of South Sumatra Number 201/KPTS/DINKES/2020 concerning Case Referral Hospitals Corona Virus Disease 2019 in South Sumatra Province. Aditya et., al, argues that last December 2019 in Wuhan, Hubei Province, was the first indication of cases pneumonia mysterious ones associated with a market in Wuhan [1]. Since December 31, 2019 January 2020 there was a significant increase in cases with the discovery of 44 cases. Day by day this virus is spreading, starting from spreading in various provinces in China, until finally reaching countries, be it Europe, America, to Asia, such as Thailand, Japan, Korea, and not to mention Indonesia. Until March 12, 2020 WHO ( World Health Organization ) declared COVID-19 a pandemic. First case COVID-19 in China is quite severe for medical treatment, but the total amount infected people are very difficult to record. It the case fatality rate of COVID-19 Pandemic is estimated to reach 2 percent among medically treated patients. This virus can be transmitted from human to human and has spread throughout. As of April 28, 2021, with a total of 176 million infected cases and a total of 48,887 million deaths. Meanwhile in South Sumatra Province [4].

itself has obtained data on positive COVID-19 patients 22,658 cases and 1,127 cases of Covid-19 patients who died. So far, as of May 28, 2020, the SARS-CoV-2. virus has infected more than 5,817,317 people with 216 people infected countries, and WHO has established a global pandemic status [2]. For this reason, a solution is needed to break the Covid chain, one of which is a detection application that can be used as a supporter in decision making to find out people who are indicated by Covid-19. In this application, the method will be applied later Machine Learning by using Convolutional Neural Network (CNN) which will detect using an X-ray of the lungs. This method will read pixels from the image so that the image is based on a prearranged reference so that the image matching process occurs in decision making by the application [5]. 


\section{RESEARCH METHODOLOGY}

\subsection{Forward Chaining}

Determination of symptoms which will later assist the process of detecting COVID-19 in patients at Siti Fatimah Hospital by utilizing the method Forward Chaining [6].

Table 1. Rule Based System

\begin{tabular}{|c|c|l|}
\hline No & Code & \multicolumn{1}{|c|}{ Symptom } \\
\hline $\mathbf{1 .}$ & G1 & Fever \\
\hline $\mathbf{2 .}$ & G2 & Cough \\
\hline $\mathbf{3}$. & G3 & Shortness of breath \\
\hline $\mathbf{4}$ & G4 & chest pain \\
\hline $\mathbf{5}$ & G5 & Flu \\
\hline $\mathbf{6}$ & G6 & Headache \\
\hline $\mathbf{7}$ & G7 & Muscle pain \\
\hline $\mathbf{8}$ & G8 & Lost Sense of Taste and Smell \\
\hline $\mathbf{9}$ & G9 & Diarrhea \\
\hline $\mathbf{1 0}$ & G10 & productive cough \\
\hline
\end{tabular}

Table 2. Illness And Solution

\begin{tabular}{|c|c|c|c|}
\hline No & Code & Disease & Solutions \\
\hline 1. & $\mathrm{C} 19$ & Covid-19 & $\begin{array}{l}\text { 1. Usemask } \\
\text { 2. Keep theby hand washing and } \\
\text { use handsanitizer } \\
\text { 3. Use a tissue when sneezing } \\
\text { and coughing }\end{array}$ \\
\hline 2. & I & Influenza & $\begin{array}{l}\text { 1. Increase rest } \\
\text { 2. Consumption of foods } \\
\text { containing Vitamin C } \\
\text { 3. Increase consumption of } \\
\text { water }\end{array}$ \\
\hline
\end{tabular}

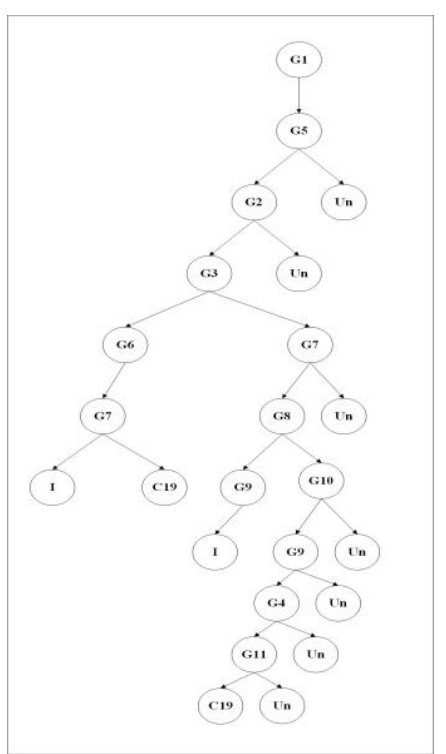

Figure. 1. Rule Based System
Table 3. Rule Based System

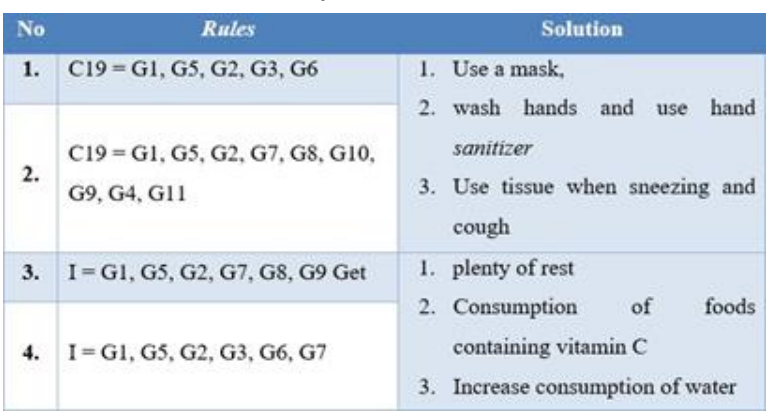

\section{CONVOLUTIONAL NEURAL NETWORK}

\subsection{Convolutional Layer}

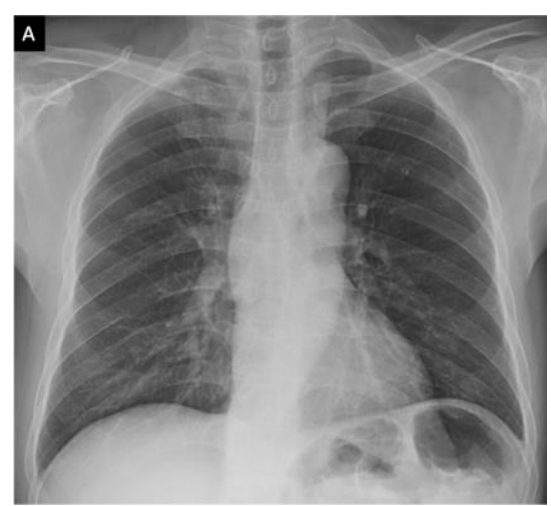

Figure 2. X-ray Photo of Covid-19

Convolutional Layer is the initial part after the input layer in the architecture CNN. This stage performs the comvolution process on the output of the previous layer and the main processes that underlie the CNN architecture. Convolution is the application of a function to the output of another function repeatedly. The convolution operation is an operation with two realvalued argument functions and applies the output function as a feature map of the input image. Input and output can be seen as two real-valued arguments. Picture 3.6 above is an image measuring $489 \times 489$ pixels which is actually a multidimensional array with a size of $489 \times 489 \times 3$ ( 3 is the number of channels). The convolutional layer consists of neurons arranged in such a way that they form a filter with length and height (pixels). For example, the first layer in the feature extraction layer is usually conv. layer with size $5 \times 5 \times 3.5$ pixels long, 5 pixels high and 3 pieces thick / total according to the channel of the image. These three filters will be shifted to all parts of the image. Each shift will be carried out a "dot" operation between the input and the value of the filter so as to produce an output or commonly referred to as an activation map or feature map. 


\subsection{Stride}

Figures and tables should be placed either at the top or bottom of the page and close to the text referring to them if possible.

\begin{tabular}{|l|l|l|l|l|l|l|}
\hline 0 & 0 & 0 & 0 & 0 & 0 & 0 \\
\hline 0 & 1 & 1 & 1 & 0 & 0 & 0 \\
\hline 0 & 0 & 1 & 1 & 1 & 0 & 0 \\
\hline 0 & 0 & 0 & 1 & 1 & 1 & 0 \\
\hline 0 & 0 & 0 & 1 & 1 & 0 & 0 \\
\hline 0 & 0 & 1 & 1 & 0 & 0 & 0 \\
\hline 0 & 0 & 0 & 0 & 0 & 0 & 0
\end{tabular}$\quad$\begin{tabular}{|l|l|l|l|l|l|l|l|}
\hline 0 & 0 & 0 & 0 & 0 & 0 & 0 \\
\hline 0 & 1 & 1 & 1 & 0 & 0 & 0 \\
\hline 0 & 0 & 1 & 1 & 1 & 0 & 0 \\
\hline 0 & 0 & 0 & 1 & 1 & 1 & 0 \\
\hline 0 & 0 & 0 & 1 & 1 & 0 & 0 \\
\hline 0 & 0 & 1 & 1 & 0 & 0 & 0 \\
\hline 0 & 0 & 0 & 0 & 0 & 0 & 0 \\
\hline
\end{tabular}$\quad$\begin{tabular}{ll|l|l|l|l|l|}
\hline 0 & 0 & 0 & 0 & 0 & 0 & 0 \\
\hline 0 & 1 & 1 & 1 & 0 & 0 & 0 \\
\hline 0 & 0 & 1 & 1 & 1 & 0 & 0 \\
\hline 0 & 0 & 0 & 1 & 1 & 1 & 0 \\
\hline 0 & 0 & 0 & 1 & 1 & 0 & 0 \\
\hline 0 & 0 & 1 & 1 & 0 & 0 & 0 \\
\hline 0 & 0 & 0 & 0 & 0 & 0 & 0 \\
\hline
\end{tabular}

Figure 3 Stide

In Figure 3 shows a yellow kernel shift with a kernel size of $3 \times 3$ shifted by 1 both vertically and horizontally. The kernel will continue to move until it has reached all values from the image

\subsection{Zero Padding}

Zero padding is a parameter that determines the number of pixels (containing zero values) to be added on each side of the input. It is used to manipulate the output dimensions of the convolutional layer (feature map). The purpose of using zero padding is:

1) The output dimension of the conv. layer is always smaller than the input (except using a 1x1 filter with stride 1). This output will be reused as input from conv. the next layer, so that more information is wasted. Using padding, we can set the output dimensions to stay the same as the input dimensions or at least not drastically reduce. So we can use conv. a deeper layer so that more features can be successfully extracted.

2) Improved performance of the model due to conv. the filter will focus on the actual information that is between the zero padding.

\begin{tabular}{|l|l|l|l|l|l|l|}
\hline 0 & 0 & 0 & 0 & 0 & 0 & 0 \\
\hline 0 & 1 & 1 & 1 & 0 & 0 & 0 \\
\hline 0 & 0 & 1 & 1 & 1 & 0 & 0 \\
\hline 0 & 0 & 0 & 1 & 1 & 1 & 0 \\
\hline 0 & 0 & 0 & 1 & 1 & 0 & 0 \\
\hline 0 & 0 & 1 & 1 & 0 & 0 & 0 \\
\hline 0 & 0 & 0 & 0 & 0 & 0 & 0 \\
\hline
\end{tabular}

Figure 4 Example of zero padding
In Figure 3.8 is an example of giving zero padding, with the original matrix $5 \times 5$ becoming $7 \times 7$ by giving zero padding of 1 . To calculate the dimensions of the feature map, the following formula can be used

$$
\text { output }=\frac{W-N+2 P}{S}+1
$$

Figure 5 Formula

Description:

$$
\begin{aligned}
& \mathrm{W}=\text { Length } / \text { Height Input } \\
& \mathrm{I}=\text { Length } / \text { Height Filter } \\
& \mathrm{P} \quad=\text { Zero Padding } \\
& \mathrm{S}=\text { Stride }
\end{aligned}
$$

\subsection{Pooling Layer}

Pooling layer is a method to reduce the size of the matrix. The pooling layer consists of a filter with a certain size and stride that will alternately shift over the entire area feature map. There are two types of pooling that can be used, namely average pooling and maxpooling. The value taken for average pooling is the average value of pooling, while for max-pooling is the highest value of pooling. Pool layers that lie between convoluted layers repeatedly in the $\mathrm{CNN}$ architecture can progressively reduce the size of the output volume in the feature map, thereby reducing the number of parameters and network calculations aimed at controlling overfitting.

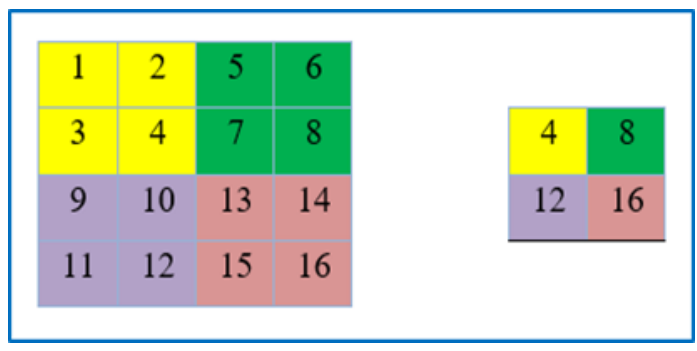

Figure 6 Max-Pooling

In Figure 6 shows an example of the use of maxpooling with matrix input of $4 \times 4$ and parameters on the kernel $2 \times 2$ and stride as much as 2 , produces a feature map of $2 \times 2$ with the highest value in each kernel.

\subsection{Fully Connected layer}

Fully-connected layer is a layer where all activation neurons from the previous layer are connected to all neurons in the next layer. This input layer is the result of the process convolution layer. All activation neurons from the previous layer will be converted into onedimensional data before being connected to the next layer, with the aim of being classified linearly[3]. 


\section{STAGE OF SYSTEM DEVELOPMENT}

\subsection{Problem Definition}

Based on interviews conducted by the author and direct questions and answers on the Covid-19 detection process. The author created a program that aims to provide convenience for the Siti Fatimah Hospital, South Sumatra Province, in diagnosing COVID-19, especially in the city of Palembang. Determination of the results of the Covid-19 diagnosis using the method Machine Learning by utilizing the algorithm Convolutional Neural Network (CNN)combined with Deep Learning

as storage data from the model determined by CNN. Where Deep Learning is an algorithm used to process images (image processing). In making this method, a data model is needed. The model data referred to here is image data Xray -of positive patients and COVID-19 negative patients. On this occasion the author used 112 positive data for Covid 19 and 112 negative data for Covid 19. Based on the data X-ray, a model was made using language programming python with h5 extension. If the model has been created with the $\mathrm{h} 5$ extension, it can be used in detecting positive and negative patients for covid-19. The flow of the application until the positive and negative results for covid 19 are determined, namely by processing data input (xrays lung-) from the user (patient) into application. The data will be used as the data is tested by application and matched based on a model created in Deep Learning algorithms using Convolutional Neural Netword (CNN), so that applications perform data processing in the form of an image (image processing) by matching whether contained re- semblance to the positive sample data for Covid-19 or not. If there is a similarity, the application will automatically provide a positive diagnosis of COVID-19 to the user (patient). On the other hand, if there is no resemblance, of course, the application will give a negative Covid-19 result that is displayed through the application.

\subsection{Feasibility Study Feasibility}

study is a process of studying and analyzing the problems that have been determined in accordance with the final objectives to be achieved. There are aspects that need to be considered in assessing a feasibility study that is viewed in terms of eligibility as follows.

1) The Technical Feasibility A technical feasibility problems if the team has a system designer can resolve the problem by using the hardware (hardware) and software (software) available, i.e. that which exists or which can be possessed. In terms of technical feasibility. Siti Fatimah Hospital, South Sumatra Province, already has hardware that meets the requirements to run this system. This hardware can be added with software supporting, namely the Google Chrome web browser and Visual Studio Code to support the implementation of the system so that this system is feasible to use,

2) Operational Feasibility A problem has operational feasibility if the system design team can solve the problem using available personnel and procedures, i.e. existing or available. In terms of operational feasibility, Siti Fatimah Hospital in South Sumatra Province already has human resources who can operate computers well. However, these human resources require training to run and develop this system so that the system procedures are feasible to implement.

3) Feasibility of Security Data stored with this new system can be said to be very safe, because this system is equipped with a password and is very secure.

\section{ANALYSIS}

\subsection{Functional Requirements Functional}

requirements in the system to be made are as follows:

1) system provides information on doctor data, disease symptom data, and diagnostic results.

2) The system can also add users such as user data (patient) and doctor data.

3) The system can manage user data by either modifying, or deleting data on the system.

4) Through this application the admin will be given a report on the patient's diagnosis data.

\subsection{Non Functional}

Needs Non-functional requirements are additional needs that do not have inputs, processes, and outputs. However, this non-functional requirement should be met because it will greatly determine whether this system will be used by the user or not. The non-functional requirements described above can be summarized in the comparison table for the old system and the new system in table 4 
Table 4. Tes

\begin{tabular}{|c|c|c|c|}
\hline No & $\begin{array}{l}\text { Type of } \\
\text { Analysis }\end{array}$ & The Old & System New system \\
\hline 1 & Performance & $\begin{array}{l}\text { Detection of } \\
\text { covid patients is } \\
\text { only focused on } \\
\text { various existing } \\
\text { test such as } \\
\text { PCR, Swab } \\
\text { Test, Antigen, } \\
\text { and so on }\end{array}$ & $\begin{array}{l}\text { The new system can } \\
\text { diagnose without } \\
\text { having to come } \\
\text { directly to the } \\
\text { hospital, and this } \\
\text { system can also } \\
\text { display or store } \\
\text { diagnostic data in the } \\
\text { database so that it } \\
\text { can be more easily } \\
\text { seen by admins and } \\
\text { doctors and the data } \\
\text { will not easily } \\
\text { damage or lost. }\end{array}$ \\
\hline 2 & Information & $\begin{array}{l}\text { Information } \\
\text { Adminregarding } \\
\text { the diagnostic } \\
\text { results is } \\
\text { minimal }\end{array}$ & $\begin{array}{l}\text { The new system } \\
\text { continuously } \\
\text { updated by the } \\
\text { application and the } \\
\text { information will be } \\
\text { automatically } \\
\text { updated according to } \\
\text { the number of users } \\
\text { who detect through } \\
\text { the application }\end{array}$ \\
\hline 3 & Economy & $\begin{array}{l}\text { It cost a lot of } \\
\text { money to } \\
\text { diagnose covid- } \\
19\end{array}$ & $\begin{array}{l}\text { No need to spend a } \\
\text { lot of money because } \\
\text { this application will } \\
\text { be able to diagnose } \\
\text { based on the } \\
\text { symptoms felt by the } \\
\text { user and only } \\
\text { requires X-rays as } \\
\text { detection component } \\
\text { a more accurate. }\end{array}$ \\
\hline 4 & Efficiency & $\begin{array}{l}\text { The old system } \\
\text { in the data } \\
\text { storage process } \\
\text { is less efficient } \\
\text { and effective }\end{array}$ & $\begin{array}{l}\text { The new system can } \\
\text { speed up the } \\
\text { diagnostic process } \\
\text { and the storage } \\
\text { process that is } \\
\text { efficient } \\
\text { effective }\end{array}$ \\
\hline
\end{tabular}

\section{CONCLUSION}

This research was conducted at Siti Fatimah Hospital, South Sumatra Province using the method Machine learning by using yahoo Convolutional Neural Network (CNN) which is used as image process. requirements in the system to be made are as follows: system provides information on doctor data, disease symptom data, and diagnostic results. The system can also add users such as user data (patient) and doctor data. The system can manage user data by either modifying, or deleting data on the system. Through this application the admin will be given a report on the patient's diagnosis data

\section{REFERENCES}

[1] A, Aditya, I, Jovian, \& B, N, Sari, 2020. Implementasi K-Means Clustering Ujian Nasional Sekolah Menengah Pertama di Indonesia Tahun $2018 / 2019$. 4, 51-58.

[2] M, Lipsitch , N, Eyal and Smith PG, 2020, Human challenge studies to accelerate coronavirus vaccine licensure. The Journal of Infectious Diseases 221(11): 1752-1756. DOI: 10.1093/ infdis,/jiaa152

[3] AKSu, Dogukan and M. Ali AYDIN, "Detection Port Scan Attemps with Comparative Analysis of Deep Learning and Support Vector Machine Algorithms," 2018.

[4] Karnovi, Riki and Roni Habibi, "Tutorial on Making a Job Progress Monitoring and Job Evaluation System Application at the Human Capital Operational Job Desk Using the Naive BayesMethod," 2020

[5] South, P, "Taken back from South Sumatra in response to Covid-19," accessed May 4, 20213

[6] Zamzam, Firdaus Fakhry, "Research Methodology Applications," CV Budi Utama., 2018. 